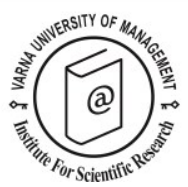

\title{
Models of Projected Image Formation of Destinations and Accommodation Establishments. An Analysis of Tour Operator Control in Promotion and Price Strategies
}

\author{
Patricia Picazo ${ }^{1}$
}

Received: 22/02/2016

\begin{abstract}
1 TIDES, Tourism and Sustainable Development Institute. University of Las Palmas de Gran Canaria. Tafira Campus, Building E - Floor 0 - Right, Saulo Torón, 4 - Las Palmas de GC, Spain. Postcode: 35017, +34 928454977, e-mail: patricia.picazo@ulpgc.es
\end{abstract}

Supervisors: Dr. Sergio Moreno Gil, smoreno@ulpgc.es

Institution awarding the Ph. D. Degree: University of Las Palmas de Gran Canaria

Date of defence: 08/02/2016

(c) 2016 Varna University of Management. All rights reserved

Citation: Picazo P. (2016) Models of Projected Image Formation of Destinations and Accommodation Establishments. An Analysis of Tour Operator Control in Promotion and Price Strategies. Doctoral Dissertation Summary. European Journal of Tourism Research 14, pp. 110-113

\section{Goal and objectives of the dissertation}

This dissertation has been developed based on a collection of four papers that deal with two large areas. On the one hand, the first two papers refer to the price structure of holiday packages offered by tour operators and the main goal is to analyse the control exerted by these intermediaries through their marketing strategies, as well as how quality and environmental indicators affect the price of the tourism product of the main sun and beach destinations. On the other hand, the second part of the thesis analyses tour operators' promotional strategies to represent the destinations and tourism establishments. The purpose of the last two papers is to propose and validate a measuring tool which is universal, innovative, comparable and dynamic, to examine the image projected by tourist destinations and accommodation establishments.

\section{Methodology}

A detailed content analysis was conducted. It examined the information published by the main European holiday groups (TUI and Thomas Cook) in the tourism catalogues over a 9-year period (2005-2014). In particular, the descriptions analysed comprised the destinations and package holidays offered in 5 countries and 15 destinations: Spain (Mallorca, Tenerife, Gran Canaria, Fuerteventura, and Lanzarote), Turkey (Turkish Riviera, Turkish Aegean coast and Istanbul), Egypt (Cairo, Luxor \& Aswan, Marsa Alam \& Berenice, Sharm el Sheikh, Hurghada), Malta and Cyprus (Southeast Coast and West Coast). In total, 5,789 packages, 1,057 visual representations of tourist destinations and 
17,187 of tourist establishments were evaluated.

For the first two papers, several ordinary least squares linear regression analyses were conducted based on the methodology of hedonic prices. On the other hand, in papers 3 and 4 , we developed a methodology based on combined techniques of content analysis and dynamic indexes of the projected image.

\section{Results}

The first paper analysed the degree of control exerted by tour operators through their promotional variables and their marketing policies on the price of holiday packages. This degree of influence varied depending on the promoted destination. Overall, the concepts and brands developed by tour operators have a positive economic impact on prices which is worth highlighting, as well as the fact of belonging to hotel chains. However, the establishments that belong to the tour operator, or those where there is some kind of agreement or bond with the intermediary, have a negative impact; thus, the negotiated prices will be lower and the tour operator will be able to increase their margins of the package holiday. In turn, and related to the specialization of tour operators in the promotion of package holidays, there is a positive relevance on the price of certain market segments worth mentioning; particularly singles with a modern lifestyle, vacation clubs which offer a wide range of sports and leisure activities, active tourists who want to be in touch with nature, single parent families, couples and Wellness and Spas. In this regard, the influence of services like a gym, Spa and Wellness, underlines the need to invest in health and well-being. Additionally, some quality indicators, such as the category awarded and promoted by the tour operator, as well as the awards and certifications obtained by the establishments, had a significant impact on the price of the holiday package. Lastly, the steep rise in the use of mobile devices, even during the holidays, renders it relevant to mention how the availability of wireless connections (Wi-Fi) has a significant and positive impact on the price, compared to internet services offered using physical computers.

Regarding paper 2, which analyses in detail the economic impact of different quality and environmental parameters featured in the description of holiday packages, the analysis on the classification systems revealed that the category exposed by the tour operator has a greater explanatory power on the price of the package than the official category assigned by each country's public institutions. More specifically, the tour operator's category has a very significant impact on the package price, whereas the official category only has a minor repercussion. Secondly, the comparison of economic impacts of environmental and quality certifications showed that the former, both the independent as well as those of tour operators, have the greatest repercussion on price. Moreover, some quality labels seem to be used as an additional type of promotion, more than a real label, representing even a decrease in the price of said establishments. In any case, those establishments interested in reflecting on the price a quality label or certification should focus on environmental ones, and particularly on those specific to the industry and which are widely implemented, allowing customers to draw comparisons between destinations and hotels. In addition, the levels of satisfaction communicated to the market, such as quality expectation indicators, had a positive effect on price, although smaller than those of tour operator category or environmental certifications. Finally, just as in paper 1, the brands and concepts generated by the tour operator turned out to have a strong influence on the price of package holidays; this seems to indicate that for the establishments of certain destinations, the tour operator's brand should be reinforced, given their weaker brand or definition of their concept.

Paper 3 show the suitability of the proposed methodology to study and evaluate the projected image of tourist destinations, allowing to analyse the homogeneity or discrepancy in the image, enabling comparisons between destinations over time, and providing useful information that will help 
improve the destination's positioning and the development of more effective promotion strategies. Similarly, applying the methodology to evaluate the projected image of the main sun and beach destinations revealed several implications about the three main categories of the study: the subject, the activities, and the context of the visual content. As regards the subject, the results showed that the presence of humans is still smaller, but with important differences in more experiential destinations. The indexes of the projected image reveal the existence of two great trends. On the one hand, there are destinations which focus on the tourist attractions instead of on the people, who are relegated to the background. On the other hand, in some destinations the presence of humans is high and the projected image tries to engage the potential tourist in the scene. In this regard, there is a clear predominance of adult tourists in the representations, although featuring different group sizes, as well as age groups according to the segmentation strategies followed by the destinations. In any case, the conclusion is that experiential representations in the projected image are still not representative in sun and beach destinations.

As regards the activities represented, most projected images show a passive and heterogeneous behaviour. However, active activities mainly focused on sport. The proposed indexes show the strategies of some destinations to position themselves as the perfect place for water sports, whereas others try to transmit a more relaxed image. In terms of contextualisation, most destinations have projected an image which is strongly linked to their natural resources, and particularly, to landscapes of their coasts. Nevertheless, there is a clear differentiation between the projected images according to the promoted destinations.

In line with paper 3 , and regarded as an additional relevant application, the fourth and last paper develops a methodology based on dynamic indexes which allow analysing the projected image of tourism establishments by evaluating the visual elements represented in their promotional material. The results of the empirical study validate the proposed methodology and confirm the applicability of the proposed indexes; it reveals significant differences in time, and between the accommodation of the different destinations included in the study. Additionally, the application of the methodology to evaluate the projected image of hotel and non-hotel accommodation located in the main sun and beach destinations revealed several trends. In the first place, the results regarding the presence of humans in the representations show a change in trend from 2005 to 2014; the presence of humans decreased considerably, it was lower than expected and the photographs played more emphasis on their individual establishments. In terms of subject type, the results show an overwhelming majority of tourists compared to all other categories; the segment aged 20 to 40 was the most popular. In terms of gender, most images feature men and women interacting together, although women play a more prominent role in the remaining images. As for the index of activities the subjects carry out, we should highlight the importance of passive activities in tourism establishments (93.33\% of images with primary relevance of the subject). More consolidated destinations present a relaxed image, marked by contemplative activities, relaxed and recreational, whereas others focus on active images, especially water sports. Within the primary active images, sports activities and games are the most important in the projected images. In general, the images show a decrease in social interaction and the recreation of experiences, in favour of passive visual elements of comfort and leisure; most of the images in the sample focused on the rooms, the drinking and dining facilities and the swimming pools.

\section{Theoretical conclusions}

Related to the first two papers, the main academic contribution is the inclusion of new tour operator and quality variables, which has traditionally been omitted and should be considered in future studies that analyse the 
impact of tour operator marketing strategies on prices. On the other hand, the present study aims to cover the gap in literature by providing a universal and representative classification of photographic material, as well as a methodology based on dynamic indices that allows the systematic evaluation of the image projected by the different types of destinations and accommodation.

\section{Practical application of the dissertation}

There are many practical implications for the different agents (establishments, tour operators and destinations). On the one hand, tour operators could improve their knowledge on the impact of their promotional elements and draw comparisons with their main competitors in the market; this would help them make decisions on their marketing and investing policies. On the other hand, it would allow establishments to understand which variables have a greater impact on the price of packages, which could improve their negotiating power with the tour operator, making their offer more attractive and adjusting it to the reality of the industry. Finally, the results help the DMOs to better develop their communication and promotion strategies and to make comparison with other rival beach destinations.

In addition, paper 3 and 4 provide the industry a universal, innovative and dynamic tool for the comparative evaluation of the projected image of tourism destinations and establishments. The methodology proposed has two main advantages: on one hand, the changes in image communicated by the competitors can be identified and the necessary adjustments can be made to the company strategy. Secondly, the information obtained through this type of study could be used for making decisions on the promotion of accommodation and destinations from a strategic level. Besides, the application of a longitudinal focus allows monitoring the representations of the establishments over time, indicating changes in the communication strategies of different organisations and showing the market trends.

\section{Content of the dissertation \\ Abstract of paper one}

The first paper tried to shed light on the degree of control exerted by tour operators through their promotional variables on the price of holiday packages. The results confirmed the relevance and influence of tour operators on prices and that the degree of influence varied depending on the promoted destination.

\section{Abstract of paper two}

The second paper analyses in detail the economic impact of different quality and environmental parameters featured in the description of holiday packages. The results revealed the great explanatory power of the tour operators rating, the positive repercussion on price of the environmental certifications and satisfaction levels and the strong influence of the brands and concepts developed by the tour operator.

\section{Abstract of paper three}

The third paper provides a comprehensive approach to evaluate the projected image of destinations. The results show the suitability of the proposed methodology, allowing analysing the homogeneity or discrepancy in the image, enabling comparisons between destinations over time, and providing useful information that will help improve the positioning and the development of more effective promotion strategies.

\section{Abstract of paper four}

The fourth paper establishes a methodology based on dynamic indices, which allows the systematic evaluation of the image projected through photographs of different types of accommodation. The results show the applicability of the proposed indices and present important differences for the establishment in the different destinations analysed. 